\title{
Population structure and long-term decline in three species of heart urchins Abatus spp. near-shore in the Vestfold Hills region, East Antarctica
}

\author{
Cecilia Carrea $^{1, *}$, Christopher P. Burridge ${ }^{1}$, Catherine K. King ${ }^{2}$, \\ Karen J. Miller ${ }^{1,3}$ \\ ${ }^{1}$ School of Biological Sciences, University of Tasmania, Hobart 7001, Tasmania, Australia \\ ${ }^{2}$ Australian Antarctic Division, Kingston 7050, Tasmania, Australia \\ ${ }^{3}$ Australian Institute of Marine Science, Perth 6009, Western Australia, Australia
}

\begin{abstract}
Patterns of fine-scale spatial population structure in Antarctic benthic species are poorly understood. There is a high proportion of brooding species in the Antarctic benthos, and a brooding life history strategy is expected to restrict their dispersal abilities and therefore foster population structure. Additionally, genetic structuring of populations can preserve signals of historic processes (such as Pleistocene glaciations) on species distributions and abundances. We developed a set of 7 microsatellite markers to examine population genetic variation and infer the demographic history of 3 sympatric Antarctic sea urchin species from the order Spatangoida (Abatus ingens, A. shackletoni and A. philippii), all with brooding life history strategies. Samples were collected at 5 sites separated by up to $5 \mathrm{~km}$, in the near-shore area surrounding Davis Station in the Vestfold Hills area of the Australian Antarctic Territory. We found evidence of a long-term population decline in all 3 species, and the estimated timing of the decline precedes anthropogenic activities and is compatible with long-term climate variability. Two genetic clusters in $A$. ingens and $A$. shackletoni suggest secondary contact after population differentiation in glacial refugia. Life history is not a good predictor of fine-scale population structure in these species, with gene flow possible at distances of $5 \mathrm{~km}$. Finally, no evidence was found for a potential impact of pollution from Davis Station on genetic variation. The reduced effective population size observed for these Antarctic benthic species highlights their fragility and the need for conservation concern.
\end{abstract}

KEY WORDS: Population structure - Demographic change - Microsatellite markers $\cdot$ Abatus · East Antarctica

\section{INTRODUCTION}

The recognition of the vulnerability of Antarctic benthic biodiversity to global warming has raised the urgency to improve our understanding of the biological processes critical for effective ecosystem management and conservation (Barnes \& Peck 2008, Barnes \& Souster 2011). In this context, the study of genetic diversity and population structure is essential to inform conservation initiatives, for example to

\footnotetext{
*Corresponding author: cecilia.carrea@utas.edu.au
}

design appropriate boundaries for marine reserves that both protect diversity within and ensure dispersal across those boundaries (Palumbi 2003). Most of our knowledge of genetic diversity in the Antarctic benthos is from large spatial scale phylogeographic studies (ca. $1000 \mathrm{~km}$ ) using mitochondrial DNA markers (Held \& Leese 2007). Intraspecific genetic structure at finer scales is less well understood, particularly in Eastern Antarctica (but see Baird et al. 2012). Patterns of genetic population structuring can

() The authors 2016. Open Access under Creative Commons by Attribution Licence. Use, distribution and reproduction are unrestricted. Authors and original publication must be credited. 
help elucidate how species survived historical climatic events in Antarctica, such as glaciations (Allcock \& Strugnell 2012), as well as provide insight into contemporary factors that may affect population divergence. Possible factors include microevolutionary processes (e.g. selection, drift) and the species' capacity for dispersal and gene flow (Thatje 2012). Comparative multi-species approaches are particularly well suited to help elucidate the main processes shaping population genetic differentiation in the Antarctic benthos, given potential idiosyncrasies of individual species responses (Baird et al. 2011).

The advance of grounded ice sheets across the Antarctic shelf has been advocated as a process that largely eradicated proximate benthic communities during the Last Glacial Maximum (LGM) (Thatje et al. 2005). Different hypotheses have been proposed to explain how the benthic fauna survived glacial periods: (1) in the deep sea (Thatje et al. 2005, 2008), (2) in ice-free refugia on the Antarctic shelf (Rogers 2007) and (3) in subantarctic islands (GonzálezWevar et al. 2013). In a recent review of the genetic patterns observed for Antarctic benthic species, Allcock \& Strugnell (2012) show that populations of low dispersive species considered to have recolonized from deep sea refugia have higher haplotype diversity than those considered to have survived in shelf refuges, since the latter would have experienced massive reductions in their effective sizes. Isolation in multiple glacial refugia, in combination with subsequent limited dispersal, has likely resulted in deep genetic population divergences involving cryptic speciation in numerous taxa (Allcock \& Strugnell 2012).

Early life history strategies (e.g. direct development vs. broadcaster spawning with a dispersal larval stage) can hinder or promote dispersal, with direct implications for population-genetic structuring (Wright 1943). Meta-analyses have supported theoretical predictions of a link between life history and dispersal potential in some marine taxa (Bradbury et al. 2008, Selkoe \& Toonen 2011), but in other comparative studies, such a relationship is not clear (Riginos et al. 2011), indicating that the underlying mechanisms are not fully understood. At small spatial scales, the correlation between dispersal ability and genetic structure shows a better fit than at larger distances (Selkoe \& Toonen 2011, Riginos et al. 2011). For example, genetic structure was found at distances as small as $300 \mathrm{~m}$ in a brooding sea star, while a congeneric and sympatric species with a larval stage showed no significant structure (Barbosa et al. 2013). Most studies have focused on lower-latitude species (Bradbury et al. 2008), partly because polar specimens are more difficult to collect, direct methods to estimate dispersal are difficult to implement at high latitudes, and species-specific fast-evolving genetic markers have generally been scarce for polar species (Held \& Leese 2007). To our knowledge, there are only a few studies on fine-scale population structure in Antarctic brooding invertebrates (Baird et al. 2012, Hoffman et al. 2013), and both were consistent with the expectation of direct development resulting in population differentiation. Hoffman et al. (2013) found genetic population structure in the gastropod Margarella antarctica at a scale of $<10 \mathrm{~km}$, and Baird et al. (2012) found limited gene flow across distances of $30 \mathrm{~km}$ in the amphipod Orchomenella franklini around Casey and Davis stations in East Antarctica.

Effective population size is a critical parameter for conservation purposes because it can help predict the effects of inbreeding and the loss of genetic diversity due to genetic drift in natural populations (Frankham 1995). Molecular studies using fast-evolving markers, such as microsatellites, can help to detect recent changes in a population's effective size (Beaumont 1999). For example, studies using microsatellite markers have been able to detect the genetic signal of population declines induced by anthropogenic environmental changes 50 to $60 \mathrm{yr}$ ago (Goossens et al. 2006, Fontaine et al. 2012, Tison et al. 2015). In Antarctica, it has been impractical to directly measure population sizes of benthic marine invertebrates, and therefore, genetic data represent a valuable tool in this context to test for changes in effective population size. Recently, differences in community composition and reduced benthic biodiversity were associated with environmental contamination by pollutants discharged to coastal waters adjacent to 2 stations in East Antarctica (Stark et al. 2014). Changes in effective population size as well as in the genetic diversity of benthic species can be expected from population declines (associated with increased mortality) in areas impacted by pollution. However, such expectations have rarely been tested, but Baird et al. (2012) found reduced genetic diversity in an amphipod associated with localized pollution impacts at Davis and Casey stations in East Antarctica.

The genus Abatus (Schizasteridae, Spatangoida) comprises 11 known species endemic to the subantarctic and Antarctic, 5 of which occur around the coastline of Davis station (A. Miskelly pers. comm.). All species have direct development, and their offspring are protected within the female's brood 
pouches until they are released to the environment as juveniles (Poulin \& Feral 1994). Abatus cordatus (endemic to the Kerguelen Islands) shows evidence of population structure on spatial scales smaller than $1 \mathrm{~km}$, as inferred by 2 allozymes (Poulin \& Feral 1994) and by 3 microsatellite and 2 intron markers (Ledoux et al. 2012). Based on these studies, low dispersal capabilities for other Antarctic brooding Abatus species are expected.

Here, we use 7 microsatellite markers to compare the fine-scale genetic structuring of 3 sympatric Abatus species (A. ingens, $A$. shackletoni and A. philippii) from inshore waters around Davis Station in the Vestfold Hills region of the Australian Antarctic Territory. The same set of markers is used for all species, thereby reduc-

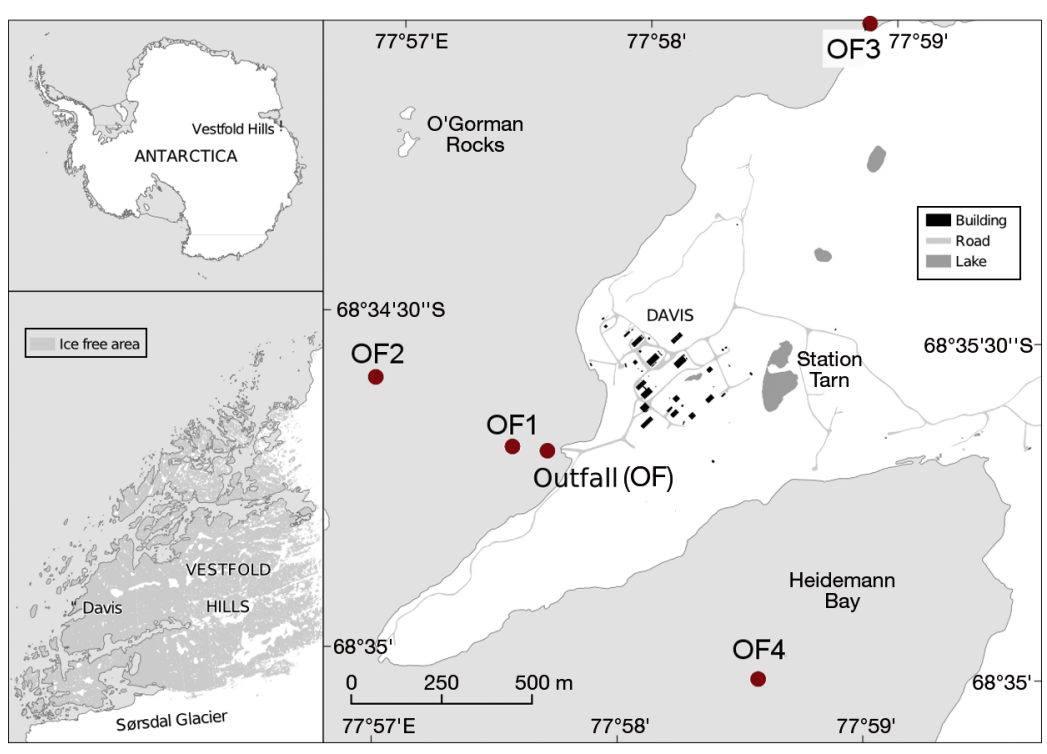

Fig. 1. Five sampling sites around Davis station, East Antarctica. The outfall (OF), OF1 and OF2 sites are considered highly impacted by the station's wastewater discharge. OF3 and OF4 are reference non-impacted sites ing potential bias during interspecific comparisons. Our main aim is to infer the demographic history and patterns of population genetic diversity and structuring of these brooding heart urchin species, to improve our understanding of the processes affecting population differentiation in the Antarctic benthos. Populations are expected to have expanded since the LGM, approximately $15 \mathrm{kyr}$ ago (Huybrechts 2002), but a recent local population decline may have resulted from the impact of anthropogenic pollutants. Furthermore, patterns of finescale genetic structure are expected to reflect low dispersal abilities and be similar among species based on sympatry and the shared presence of a brooding life history. Secondarily, potential impacts of pollution from the Davis Station wastewater discharge on the genetic diversity and effective population size of these species are tested.

\section{MATERIALS AND METHODS}

\section{Study area}

Individuals of 3 species of Abatus were collected in the near-shore area surrounding Davis Station (68 34' 36" S, 7758' 03"E) located on Prydz Bay, Vestfold Hills, in Princess Elizabeth Land, East Antarctica (Fig. 1, see also Table 2): A. ingens ( $\mathrm{N}=112)$, A. shackletoni $(\mathrm{N}=93)$ and $A$. philippii $(\mathrm{N}=44)$. $\mathrm{A}$ recent evaluation of the dispersion and dilution of wastewater at Davis Station found that elevated lev- els of toxic contaminants (metals, polybrominated diphenyl ethers, nutrients and faecal sterols) are accumulating within $2 \mathrm{~km}$ of the station's outfall (Stark et al. 2015). Samples were collected from 5 sites (red dots in Fig. 1, sampling size per site in Table 2), and the largest distance between any 2 sampling sites was $5 \mathrm{~km}$. Three of the sites are considered heavily impacted: OF (outfall), OF1 and OF2 are within $500 \mathrm{~m}$ of the outfall pipe. The 2 control sites are considered to have negligible impact from the wastewater discharge; OF3 is located $\sim 2.4 \mathrm{~km}$ from the outfall pipe to the northeast, and OF4 $\sim 2.6 \mathrm{~km}$ to the southwest (Fig. 1). Moreover, the OF3 and OF4 sites are both removed from the predominant longshore flow that transports the wastewater plume southeastwards along the coast (Stark et al. unpubl.). Samples from OF1 and OF2 were collected at 4.5-7.0 $\mathrm{m}$ and 10-12 $\mathrm{m}$ depths, respectively, during the 2009/2010 Antarctic field season, and samples from OF, OF3 and OF4 were taken at depths $<4$ m during the 2012/2013 season.

\section{Microsatellite development and genotyping}

Microsatellite markers were developed from the genome of 3 Abatus ingens individuals. An enriched library was made by Ecogenics (Zurich) from sizeselected genomic DNA ligated into SNX forward/ SNX reverse linker (Hamilton et al. 1999) and enriched by magnetic bead selection with biotin- 
labelled $(\mathrm{CT})_{13},(\mathrm{GT})_{13},(\mathrm{AAC})_{10}$ and $(\mathrm{AAG})_{10}$ oligonucleotide repeats (Gautschi et al. 2000a,b). Of 528 recombinant colonies screened, 315 gave a positive signal after hybridization. Plasmids from 152 positive clones were sequenced, and primers were designed for 32 microsatellite inserts, of which all were tested for polymorphism in $15 \mathrm{~A}$. ingens individuals. Seven loci were suitable for population-level analyses (Table 1). Additionally, cross-species amplification was successful in A. shackletoni and A. philippii (Table S1 in the Supplement at www.int-res.com/ articles/suppl/m545p227_supp.pdf).

Genomic DNA was extracted from approximately $20 \mathrm{mg}$ of gonad tissue from each individual, using the DNeasy Blood and Tissue Kit (QIAGEN) following the manufacturer's instructions. Primers were labeled with WellRED fluorescent dyes (Beckman Coulter) and three multi-locus PCR panels were designed (Table 1). Multiplex PCRs were performed using $12.5 \mu \mathrm{l}$ reactions containing Multiplex PCR Mastermix (QIAGEN), Primer mix (final concentration varied for each primer) and 10 to $100 \mathrm{ng}$ of template DNA. Fragments were separated on an automated sequencer (CEQ 8000, Beckman Coulter), and fragment size was scored using the CEQ 8000 Genetic Analysis System software v.8.0.

Genotypes were examined with MICROCHECKER (Van Oosterhout et al. 2004) to detect potential genotyping errors resulting from null alleles, large allele drop-out or PCR stuttering. Datasets were formatted using Convert (Glaubitz 2004) and PGDSpider 2.0 (Lischer \& Excoffier 2012) for use in other software packages. The null hypothesis of genotype frequencies under Hardy-Weinberg (HWE) equilibrium and linkage disequilibrium (LD) among loci were tested by exact tests (Guo \& Thompson 1992) and G-tests (Weir 1996) respectively, using Genepop 4.0 (Raymond \& Rousset 1995). A sequential Bonferroni correction sensu Rice (1989) was applied to significance levels for tests of HWE and LD. Departures from HWE expectations were further examined by calculation of Weir \& Cockerham's (1984) fixation index, $F_{\mathrm{IS}}$, to determine the excess $\left(F_{\mathrm{IS}}<0\right)$ or deficit $\left(F_{\mathrm{IS}}>0\right)$ of heterozygotes. The influence of selection was tested with a Bayesian approach using BayeScan 2.1 (Foll \& Gaggiotti 2008). Each species' data set was tested separately, using the default parameters for the Monte Carlo Markov Chain (MCMC; total number of iterations $=10^{5}$ ), except the number of pilot runs was doubled to 40 .

\section{Genetic diversity among species and populations}

Mean observed and expected heterozygosities, number of alleles, number of private alleles, and percentage of polymorphic loci for each sampling location were calculated using GenAlEx 6.5 (Peakall \& Smouse 2012). To compensate for differences in sample size when comparing genetic diversity among geographic sites, allelic richness and private allelic richness (unique alleles in a population) were calculated using the rarefaction method implemented in HP-RARE (Kalinowski 2005). Three group comparisons were carried out by permutation tests in FSTAT 2.9.3 (Goudet 1995) using 10000 permutations: (1) expected heterozygosity $\left(H_{\mathrm{e}}\right)$ was compared among species, (2) allelic richness was compared among

Table 1. Characterization of 7 microsatellite loci developed for Abatus ingens. Dyes: D2 = black; D3 = green; D4 = blue

\begin{tabular}{|c|c|c|c|c|c|}
\hline $\begin{array}{l}\text { Multiplex } \\
\text { panel }\end{array}$ & $\begin{array}{l}\text { PCR thermal } \\
\text { protocol }\end{array}$ & Locus & $\begin{array}{l}\text { Primer sequence } \\
\left(5^{\prime}-3^{\prime}\right)\end{array}$ & Dye & $\begin{array}{l}\text { Nucleotide } \\
\text { repeats }\end{array}$ \\
\hline 1 & $\begin{array}{l}15 \mathrm{~min} \text { at } 95^{\circ} \mathrm{C} \\
{\left[30 \mathrm{~s} \text { at } 95^{\circ} \mathrm{C}\right.} \\
90 \mathrm{~s} \text { at } 62^{\circ} \mathrm{C} \\
\left.60 \mathrm{~s} \text { at } 72^{\circ} \mathrm{C}\right] \\
\times 34\end{array}$ & $\begin{array}{l}\text { Ab_07 } \\
\text { Ab_15 }\end{array}$ & $\begin{array}{l}\text { F: CTCGAGACTCCATCTTCTAGTCC } \\
\text { R: CACAGATACGTCTTACCACTTCG } \\
\text { F: GCCATTAAGTTCCCCAAAGAG } \\
\text { R: CGGTTTGCTTGTCATTTTTAGC }\end{array}$ & D2 & $\begin{array}{c}(\mathrm{TCT})_{15} \ldots(\mathrm{TCA})_{8} \\
(\mathrm{GTT})_{22}\end{array}$ \\
\hline 2 & $\begin{array}{l}15 \mathrm{~min} \text { at } 95^{\circ} \mathrm{C} \\
{\left[30 \mathrm{~s} \text { at } 95^{\circ} \mathrm{C}\right.} \\
90 \mathrm{~s} \text { at } 62^{\circ} \mathrm{C} \\
\left.60 \mathrm{~s} \text { at } 72^{\circ} \mathrm{C}\right] \\
\times 34\end{array}$ & $\begin{array}{l}\text { Ab_16 } \\
\text { Ab_17 } \\
\text { Ab_31 }\end{array}$ & $\begin{array}{l}\text { F: CCCCTCGCATCATCTGTAAG } \\
\text { R: GAAGAACAACAACAAGAACTTGAATAG } \\
\text { F: GAGCAAACCACCCGTTG } \\
\text { R: ACTGTGCGTCAAATCAAACG } \\
\text { F: GAGTGTGGTGCTGTGAGGTG } \\
\text { R: TACAATGTGCCTCCCGTCTC }\end{array}$ & D2 & $\begin{array}{l}(\mathrm{CAT})_{10} \\
(\mathrm{GAA})_{8} \\
(\mathrm{GCT})_{6}\end{array}$ \\
\hline 3 & $\begin{array}{l}15 \mathrm{~min} \text { at } 95^{\circ} \mathrm{C} \\
{\left[30 \mathrm{~s} \text { at } 95^{\circ} \mathrm{C}\right.} \\
90 \mathrm{~s} \text { at } 60^{\circ} \mathrm{C} \\
\left.60 \mathrm{~s} \text { at } 72^{\circ} \mathrm{C}\right] \\
\times 34\end{array}$ & $\begin{array}{l}\text { Ab_18 } \\
\text { Ab_29 }\end{array}$ & $\begin{array}{l}\text { F: CATTTATCTGTCATCCTTTCACG } \\
\text { R: TGGAGGAAAAATAAACGAGGAG } \\
\text { F: GGCCGGGAGGATACTTTTAC } \\
\text { R: GGGTCAAGGTAAGGAGACAG }\end{array}$ & $\begin{array}{l}\text { D4 } \\
\text { D3 }\end{array}$ & $\begin{array}{l}(\mathrm{TCT})_{8} \\
(\mathrm{ACA})_{6}\end{array}$ \\
\hline
\end{tabular}


sites within species, and (3) allelic richness was compared between impacted and non-impacted sites within species.

\section{Genetic differentiation}

We performed a Bayesian hierarchical approach implemented in STRUCTURE (Pritchard et al. 2000), including all individuals regardless of morphologically defined species, to examine genetic clustering and detect potential taxonomic misidentifications. Subsequently, data for each species was analysed separately to examine intra-specific groupings. A LOCPRIOR model, with sampling location as prior information, was used to assist the clustering (Hubisz et al. 2009) and estimate the coancestry of each individual to a number of genetic groups (K) within each species. In each case, 5 iterations for each $K$ ( $K$ from 1 to 7 ) were run under the Admixture model with correlated allele frequencies. A total of 450000 Markov Chain Monte Carlo replicates were run for each analysis, with a burn-in length of 150000 . Consistent parameter values were obtained from independent runs indicating an appropriate run length for parameter accuracy. The most likely $\mathrm{K}$ was determined by the highest posterior probability method (Pritchard et al. 2000) and the Evanno et al. (2005) method as implemented in STRUCTURE HARVESTER 0.6 (Earl \& vonHoldt 2012).

Genetic differentiation among sampling sites within each species was tested using analysis of molecular variance (AMOVA) (Excoffier et al. 1992) based on $F_{\mathrm{ST}}$ (Meirmans 2006), implemented by GenAlEx. In addition, the diversity partitioning measure $G_{\mathrm{ST}}$ (Nei 1973) and differentiation statistics $G_{\text {ST }}^{\prime}$ (Hedrick 2005) and $D_{\text {EST }}$ (Jost 2008) were calculated for each pair of sampling locations to explore the spatial patterns of differentiation, using the $\mathrm{R}$ package DiveRsity 1.9 (Keenan et al. 2013). Finally, to analyse trends observed in the data, confidence intervals at the $95 \%$ level were calculated for each statistical measure and visualization plots were obtained with DiveRsity. Significance for the pairwise $D_{\mathrm{EST}}$ statistics was calculated with GenAlex based on 10000 permutations.

\section{Demographic parameters}

We used a Bayesian coalescent-based approach to estimate posterior probabilities for demographic parameters as implemented in Msvar 1.3 (Beaumont 1999a, Storz \& Beaumont 2002). The method's demographic model has 4 estimated parameters: current effective population size $\left(N_{0}\right)$, ancestral effective population size $\left(N_{1}\right)$, time since the demographic change occurred $(\mathrm{Ta})$ and mutation rate $(\mu)$ of microsatellite loci (assumed to evolve under a stepwise mutation model). This model assumes a panmictic population of size $N_{0}$ that has changed (expanded or declined) exponentially since Ta years ago. Therefore, for each species, we included a subsample of 43 A. ingens individuals (pooled from OF and OF1), 37 A. shackletoni individuals (pooled from OF and OF1) and 27 A. philippii individuals (pooled from OF and OF3). Each subsample corresponds to a single genetic cluster inferred by STRUCTURE (with Q > 0.9) and pooled from sampling sites represented by non-significant pairwise differentiation measures (i.e. considered panmictic).

Three Msvar runs were performed for each of the 3 species; run lengths were $1 \times 10^{9}$ iterations with a thinning interval of 20000 steps. Different starting values of the model parameters and random seeds were set for each independent run. Flat 'uninformative' priors were chosen for the parameters. The first $10 \%$ of the total number of steps were discarded (burn-in). We assumed a generation time of $20 \mathrm{yr}$ (average parental age in the population). This assumption is based on the fact that the Antarctic species are expected to have longer life spans than temperate echinoids (that can live 10 to $20 \mathrm{yr}$ ), with the Antarctic species possibly reaching a maximum age of $50 \mathrm{yr}$ (Brey 1991). Convergence among the 3 MCMC runs was assessed visually and by using the Gelman \& Rubin (1992) diagnostic implemented in the package CODA 0.16-1 (Plummer et al. 2006) in R. The posterior distributions of the model parameters were estimated by combining the 3 convergent runs to improve precision. Median values and $95 \%$ highest posterior density (HPD) intervals for each parameter were estimated with CODA.

To detect changes in population size, and the magnitude of such change, we calculated the mean of the ratio between current and past population size (r) as $\log _{10}(\mathrm{r})=\log _{10}\left(N_{0} / N_{1}\right)$ following Chikhi et al. (2010). In addition, to evaluate the strength of evidence for a population decline versus a population expansion, we performed a Bayes Factors (BF) analysis in R for each species. BF were calculated as the ratio between the number of states in the chain with negative values of $r$ (population decline) over the number of states in the chain with positive values of $r$ (population expansion). BF equal to 1 indicate similar evidence for the 2 scenarios, while BF $>1$ favour the population decline hypothesis, and values $>7$ are considered significant (Storz \& Beaumont 2002). 


\section{RESULTS}

\section{Genotyping error and neutrality tests}

Allele frequencies by locus and sampling site for the 3 species are shown in Fig. S1 in the Supplement. Two of $105 \mathrm{LD}$ tests were significant for each of $A$. ingens and $A$. shackletoni (none in the case of $A$. philippii), but no test remained significant after sequential Bonferroni correction. Two of 35 HWE exact tests remained significant after the sequential Bonferroni for $A$. ingens, with 6 of 35 for A. shackletoni and 1 of 21 in the case of A. philippii (Table S2 in the supplement). Departures from HWE were all heterozygote deficits (positive $F_{\mathrm{IS}}$ values), but they did not involve a specific locus in multiple sampling sites, except for the case of Ab_18 for A. shackletoni (Table S2). Therefore, subsequent analyses were performed both including and excluding this locus, but no effects on the results were detected. The same approach was taken with 2 outlier loci (Ab_16 and Ab_17) identified with BayeScan, for A. shackletoni. Negative alphas obtained for both outlier loci are indicative of balancing selection. No outlier loci were detected for A. ingens or A. philippii.

\section{Genetic diversity}

Genetic diversity was low in the 3 species; expected heterozygosities ranged from 0.38 to 0.49 in A. ingens, from 0.53 to 0.56 in A. shackletoni and from 0.43 to 0.46 in A. philippii (Table 2). Allelic rich- ness and private allele diversity were not significantly different among sites in any of the 3 species or within species with respect to the distance to the station outfall (Table 2). However, comparisons among species showed that $A$. shackletoni is genetically more diverse than $A$. ingens and A. philipii $(\mathrm{p}<0.01)$; there was no difference in genetic diversity between A. ingens and A. phillipii.

\section{Genetic differentiation}

When data from all individuals were included in the STRUCTURE analysis, 3 genetic groups were inferred corresponding to the 3 Abatus species sampled (Fig. 2). Notably, 4 individuals showed admixed genotypes between $A$. ingens and A. philippii, suggesting hybridization (Fig. 2). Potential hybrid individuals were removed from further analyses. Patterns of spatial population structure differed among species. Two genetic clusters were inferred with STRUCTURE for both $A$. ingens and A. shackletoni (Fig. 2). Individuals of $A$. ingens belonging to each of the 2 inferred genetic groups were spread across sampling sites, and individuals admixed to varying degrees were present within sites (Fig. 2). Abatus shackletoni individuals from OF1 and OF2 correspond mostly to one of the inferred genetic groups, while individuals from OF3 and OF4 correspond mostly to the other inferred group (despite being separated by approximately $5 \mathrm{~km}$ ); individuals from OF exhibited a continuum in their allocation to these groups (Fig. 2). Only a single genetic group was inferred for A. philippii with STRUCTURE (results not shown).

Table 2. Genetic diversity indexes (observed heterozygosity $H_{\mathrm{o}}$ expected heterozygosity $H_{\mathrm{e}}$ ) and sampling size per Abatus species and per sample location at Davis Station, East Antarctica. Where applicable, values are mean $\pm \mathrm{SE}$

\begin{tabular}{|c|c|c|c|c|c|c|c|c|c|}
\hline Species & $\begin{array}{l}\text { Sampling } \\
\text { location }\end{array}$ & $\mathrm{N}$ & $H_{\mathrm{o}}$ & $H_{\mathrm{e}}$ & $\begin{array}{l}\text { Allelic } \\
\text { richness }\end{array}$ & $\begin{array}{l}\text { No. of } \\
\text { alleles }\end{array}$ & $\begin{array}{l}\% \text { of poly- } \\
\text { morphic } \\
\text { loci }\end{array}$ & $\begin{array}{l}\text { No. of } \\
\text { private } \\
\text { alleles }\end{array}$ & $\begin{array}{c}\text { Private } \\
\text { allelic } \\
\text { richness }\end{array}$ \\
\hline \multirow[t]{5}{*}{ A. ingens } & OF & 22 & $0.34 \pm 0.1$ & $0.38 \pm 0.1$ & 2.90 & $3.29 \pm 0.8$ & 71.4 & 0 & 0.00 \\
\hline & OF1 & 36 & $0.49 \pm 0.1$ & $0.45 \pm 0.1$ & 3.39 & $4.57 \pm 1.3$ & 85.7 & 5 & 0.42 \\
\hline & OF2 & 16 & $0.41 \pm 0.1$ & $0.38 \pm 0.1$ & 2.33 & $2.86 \pm 0.6$ & 71.4 & 0 & 0.00 \\
\hline & OF3 & 17 & $0.43 \pm 0.1$ & $0.42 \pm 0.1$ & 3.09 & $3.57 \pm 0.9$ & 71.4 & 1 & 0.33 \\
\hline & OF4 & 21 & $0.51 \pm 0.1$ & $0.49 \pm 0.1$ & 3.45 & $4.71 \pm 1.0$ & 85.7 & 3 & 0.42 \\
\hline \multirow[t]{5}{*}{ A. shackletoni } & OF & 17 & $0.40 \pm 0.1$ & $0.53 \pm 0.1$ & 3.10 & $4.0 \pm 0.9$ & 85.7 & 1 & 0.09 \\
\hline & OF1 & 32 & $0.56 \pm 0.1$ & $0.56 \pm 0.1$ & 3.62 & $5.7 \pm 1.1$ & 100 & 7 & 0.49 \\
\hline & OF2 & 7 & $0.61 \pm 0.1$ & $0.54 \pm 0.1$ & 3.13 & $3.6 \pm 0.3$ & 100 & 2 & 0.47 \\
\hline & OF3 & 19 & $0.49 \pm 0.1$ & $0.53 \pm 0.1$ & 2.96 & $4.14 \pm 1.1$ & 85.7 & 2 & 0.23 \\
\hline & OF4 & 18 & $0.48 \pm 0.1$ & $0.55 \pm 0.1$ & 3.15 & $3.8 \pm 0.9$ & 85.7 & 1 & 0.22 \\
\hline \multirow[t]{3}{*}{ A. philippii } & $\mathrm{OF}$ & 12 & $0.39 \pm 0.1$ & $0.43 \pm 0.1$ & 2.49 & $2.7 \pm 0.4$ & 85.7 & 1 & 0.15 \\
\hline & OF3 & 15 & $0.36 \pm 0.1$ & $0.46 \pm 0.1$ & 2.54 & $2.7 \pm 0.5$ & 85.7 & 2 & 0.23 \\
\hline & OF4 & 17 & $0.38 \pm 0.1$ & $0.43 \pm 0.1$ & 2.61 & $2.8 \pm 0.4$ & 85.7 & 4 & 0.37 \\
\hline
\end{tabular}



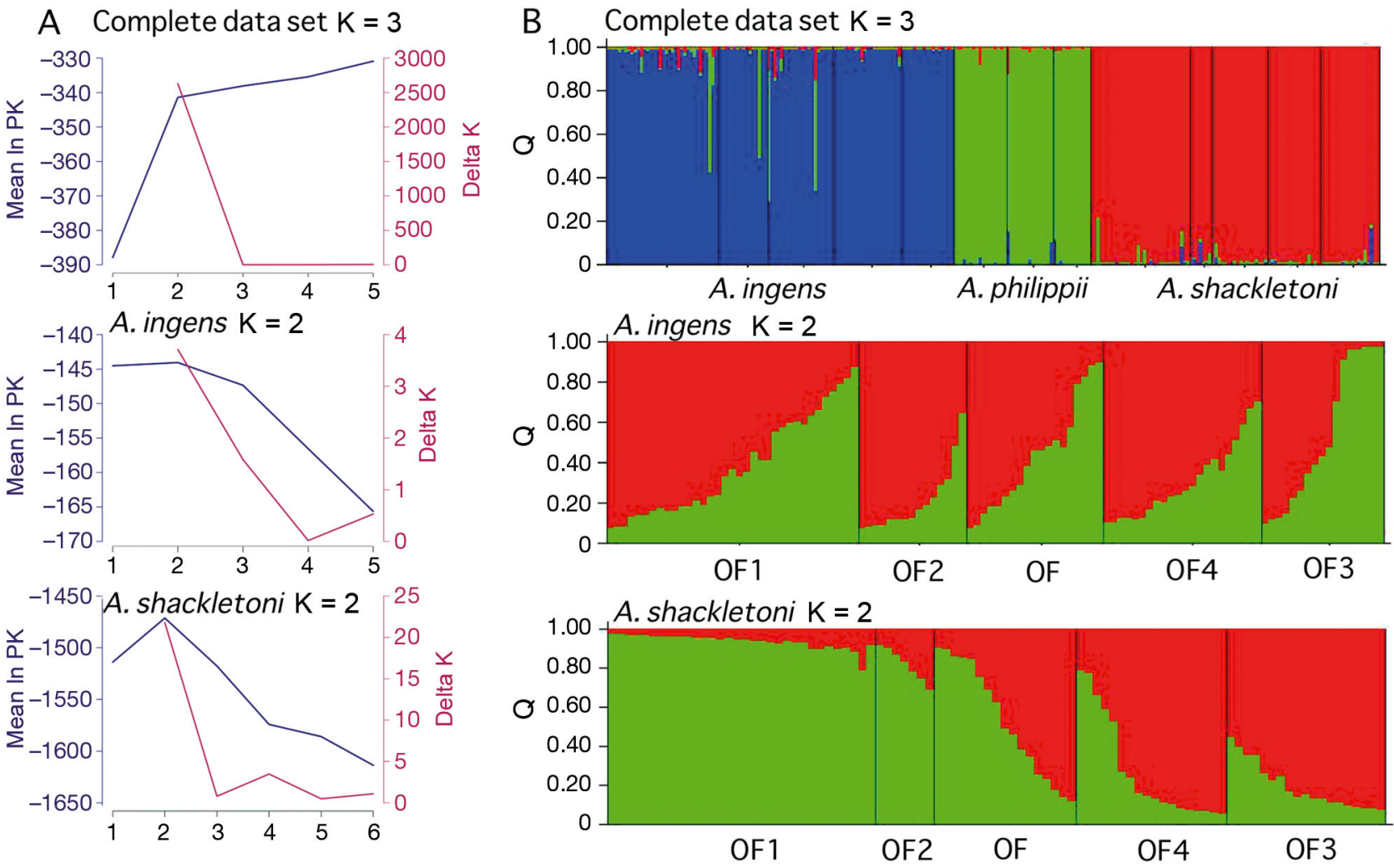

Fig. 2. (A) Most likely K (genetic clusters) inferred by posterior probability method (blue) and Evanno et al. (2005) method (red). (B) Membership coefficient (Q) bar plots, showing genetic clusters (K) obtained with STRUCTURE. Black vertical lines separate sampling sites

The AMOVA shows significant genetic differentiation among sampling sites in A. shackletoni $\left(F_{\mathrm{ST}}=\right.$ $0.04, \mathrm{p}<0.01)$ and A. philippii $\left(F_{\mathrm{ST}}=0.05, \mathrm{p}<0.01\right)$, while the null hypothesis of no genetic differentiation among sites could not be rejected in $A$. ingens $\left(F_{\mathrm{ST}}=\right.$ $0.01, \mathrm{p}=0.12$ ). Confidence intervals for the diversity partitioning measures, $G_{\mathrm{ST}}$, and differentiation statistics, $G_{\text {ST }}^{\prime}$ and $D_{\text {EST, }}$ mostly overlap (Table S3 in the Supplement), and all estimates were significantly correlated: $\mathrm{R}_{G S T-G ' S T}=0.99(\mathrm{p}<0.01), \mathrm{R}_{G S T-D E S T}=0.87$ $(\mathrm{p}<0.01)$, and $\mathrm{R}_{D E S T-G ' S T}=0.87(\mathrm{p}<0.01)$. We therefore focused on $\mathrm{D}_{\mathrm{EST}}$ for pairwise comparisons among sites (Fig. 3). The most differentiated sites for A. ingens are OF2 relative to OF4 $(\mathrm{p}<0.01)$. In the case of A. shackletoni, the most differentiated sites were OF1 relative to OF4 $(\mathrm{p}<0.01)$ and OF1 relative to OF3 ( $p<0.01)$. Finally, for A. philippii, individuals from OF were differentiated from OF4 ( $<<0.01)$, but no other pair of sites were differentiated. Despite being separated by the greatest distances in our sam-
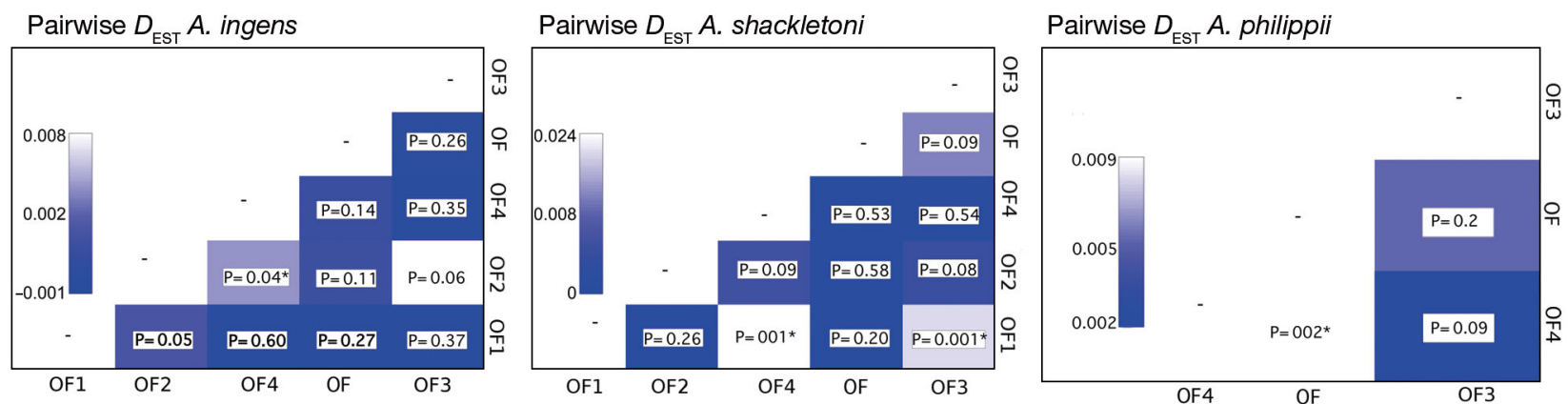

Fig. 3. Visualization of pairwise differentiation between sample sites for the 3 species, as measured by $D_{\text {EST }}$ values. The pvalues were obtained using 10000 permutations in GenAlEx; asterisks indicate statistical significance $(\mathrm{p}<0.05)$ 
ple scheme (ca. $5 \mathrm{~km})$, no significant differences were observed between non-impacted sites for any of the 3 species.

\section{Demographic history}

Bayesian estimation of current and ancestral effective population sizes shows a population decline in all 3 Abatus species (Table 3, Fig. 4). Varying the starting values and parameter priors did not alter the results. The 3 species had median

A) A. ingens

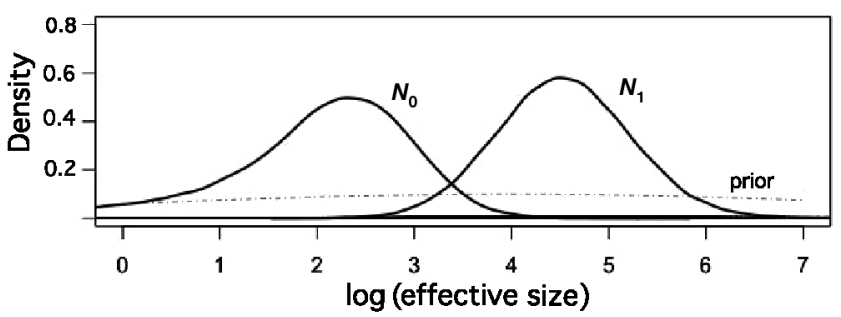

B) A. shackletoni

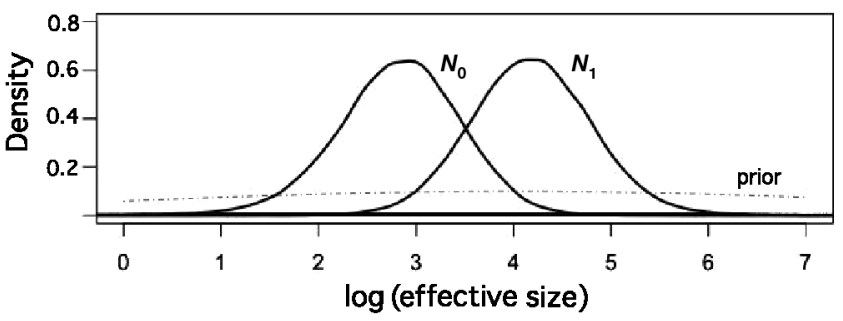

\section{C) A. philippii}

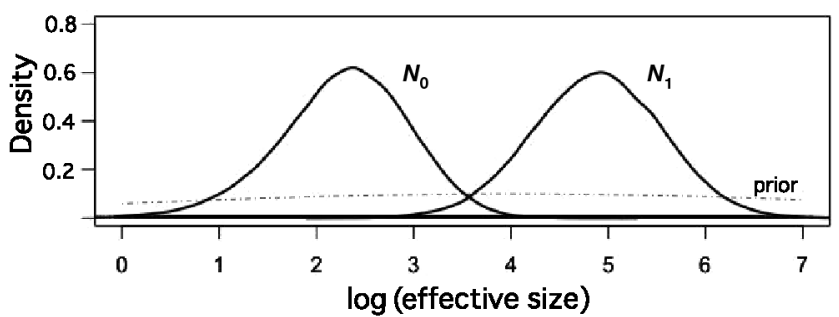

ancestral effective population sizes of approximately 30000 to 80000 individuals (Table 3), which decreased by $>90 \%$ to their current effective sizes of $<1000$ individuals. BF analysis consistently shows that evidence for a scenario of population decline is significantly stronger than for a scenario of population expansion (Table 3). Median values for the posterior distributions of $T a$ ranged between approximately $12.4 \mathrm{kyr}$ for $A$. ingens, $31.5 \mathrm{kyr}$ for A. shackletoni and $47.6 \mathrm{kyr}$ for A. philippii. The $95 \%$ HPD in each case largely overlap among species (Table 3, Fig. 4).
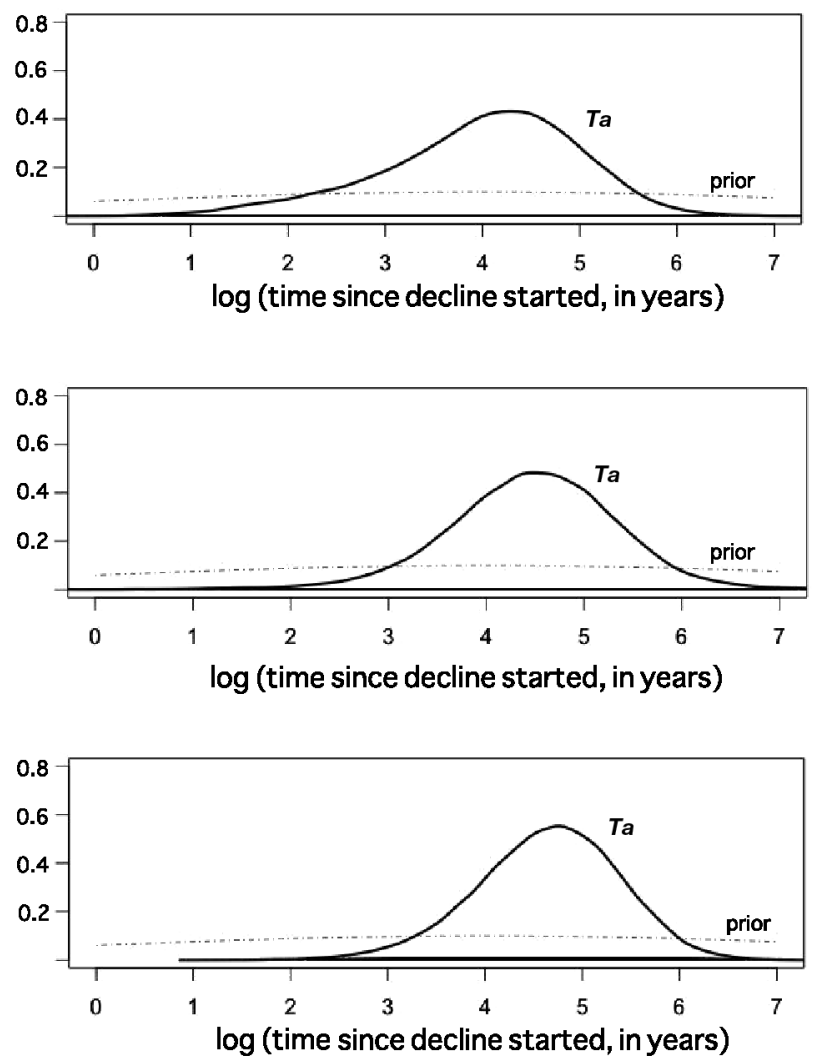

Fig. 4. Posterior density distributions of demographic parameters inferred with Msvar: $N_{0}$ (current effective population size), $N_{1}$ (ancestral effective population size), and $T a$ (time since change in effective size started) for (A) Abatus ingens, (B) A. shackletoni and (C) A. philippii

Table 3. Median values and 95\% highest posterior density (HPD) intervals (L: lower credible bound; U: upper credible bound) for the demographic parameter estimates obtained with Msvar: $N_{0}$ (current population effective size), $N_{1}$ (ancestral population effective size), and $T a$ (time since change in effective size started). Negative values for the $\log$ of the ratio between $N_{0}$ and $N_{1}\left(\log _{10}(\mathrm{r})\right)$ indicate population declines of $>90 \%$ in the 3 Abatus species. Note that there are no positive values of $\log _{10}(r)$. BF: Bayes Factors

\begin{tabular}{|lrrrrrrrrrr|r}
\hline Species & $N_{0}$ & L95\% & U95\% & $N_{1}$ & L95\% & U95\% & Ta & L95\% & U95\% & $\log _{10}(\mathrm{r})$ & BF \\
\hline A. ingens & 147.6 & 1.5 & 2105.5 & 33646.9 & 2577.8 & 490332.6 & 12385.6 & 115.1 & 269650.7 & -2.5 & 3175 \\
A. shackletoni & 691.1 & 50.5 & 6831.6 & 14986.9 & 1460.4 & 166961.2 & 31573.5 & 962.9 & 746879.8 & -1.4 & 40 \\
A. philippii & 208.2 & 12.7 & 2112.1 & 78151.4 & 5982.4 & 950459.1 & 47692.6 & 2310.6 & 618094.7 & -2.6 & Inf. \\
\hline
\end{tabular}




\section{DISCUSSION}

Our study provides genetic evidence for a remarkable long-term population decline of $>90 \%$ for 3 species of heart urchins in Prydz Bay, Eastern Antarctica. In all cases, the estimated time since the start of the decline pre-dates any possible anthropogenic impact and is therefore more compatible with the effects of long-term natural climate variability. Antarctic ice core data indicate that the last $800 \mathrm{kyr}$ have been characterized by 8 glacial cycles with a strong 100 kyr periodicity (Laurent et al. 2004). In addition, 2 genetic clusters were inferred both for $A$. ingens and A. shackletoni that suggest long-term persistence and secondary contact after the 2 populations survived in different refugia, where the populations would have diverge $d$. It has been proposed that ice-free areas existed on the shelf in Prydz Bay during the LGM (Domack et al. 1998, O'Brien et al. 1999), and these could have provided habitat for benthic organisms. Refugial populations and post-recolonization secondary population admixture has been identified in the Ross Sea (East Antarctica) in Adèlie penguins (Ritchie et al. 2004) and has been documented as a genetic legacy to glacial cycles in different species from both the Southern (Zemlak et al. 2008) and Northern (Hewitt 2000) Hemispheres. Additionally, the low genetic diversity and low effective population size observed for the 3 species could be associated with a relatively recent recolonization of the area.

Radiocarbon dating of glacial marine deposits indicates that the ice retreat in Prydz Bay occurred ca. 20 kyr ago (Anderson et al. 2002), and we can expect benthic populations to have expanded (i.e. $N_{0}>N_{1}$ ) since this deglaciation occurred. In fact, genetic evidence of a recent (ca. 10 kya) demographic expansion has been found in the congeneric A. agassizii in the Antarctic Peninsula, West Antarctica (Diaz et al. 2012). Thus, the question arises as to why East Antarctic Abatus do not appear to have recovered during the present interglacial period (i.e. $N_{0}<N_{1}$ ). One possible explanation is that the effects of glaciations may have caused particularly drastic population bottlenecks in the studied area of East Antarctica and that the time since recolonization of the region has not been long enough for these populations to recover effective sizes similar to the ones that ancestral populations had before the massive disturbance caused by glaciations. Another possibility involves regional environmental and ecological causes that should be further investigated. For example, Poulin et al. (2002) proposed that there is a rela- tionship between the impact of ice disturbance and the relative abundances of broadcaster spawners and brooders in Antarctic benthic echinoderms, with ecological dominance of broadcaster spawners when the shallow habitats are more heavily disturbed. Reductions in effective population sizes can thus be expected by competitive exclusion, e.g. by the more abundant broadcast spawner, Sterechinus neumayeri (Brey 1991), and under a scenario of regional strong disturbance. These possibilities are not mutually exclusive and may explain in combination the low inferred effective population sizes of the 3 brooding Abatus species studied.

The relationship between a species' life history strategy and its population structure is complex in marine invertebrates (e.g. Miller \& Ayre 2008). Population structure was generally weak in the 3 species we surveyed; however, some of the pairwise comparisons between sampling sites separated by $<5 \mathrm{~km}$ were significantly different in the 3 species (Fig. 3). Global $F_{\mathrm{ST}}$ values were also significant for 2 of the species (A. shackletoni and A. philippii), which is consistent with expectations for organisms that are relatively immobile (Dumont et al. 2007) and do not have a dispersive larval stage. On the other hand, individuals collected at the sites located furthest apart (OF3 and OF4) lacked genetic differentiation in all 3 species, suggesting gene flow is possible at distances of $5 \mathrm{~km}$ and that life history is not a good predictor of fine-scale population structure in these species. Evidence of dispersal across kilometres was unexpected given that the congeneric brooding species A. cordatus in the Kerguelen Islands is genetically structured over spatial scales as small as $10 \mathrm{~m}$ (Ledoux et al. 2012). In contrast to subantarctic islands, seasonal sea-ice dynamics on the shallow Antarctic shelf could have an important role promoting dispersal at fine spatial scales (Dayton et al. 1969). Likewise, passive rafting on floating substrata, including icebergs, anchor ice and kelp, has been proposed to explain long-distance dispersal in Antarctic and subantarctic brooding species (Baird et al. 2011, Nikula et al. 2013), and these means of passive dispersal may be more important for structuring populations around the Antarctic continent than in insular environments.

It can be assumed that sympatric species are affected by the same environmental factors, and therefore interspecific differences in spatial patterns of population structure suggest species-specific causes (see Figs. $2 \& 3$ ). For each of the 3 sympatric Abatus species, the most genetically differentiated site of those sampled was different: OF2 for $A$. in- 
gens, OF1 for A. shackletoni and OF for A. philippii (Fig. 3). Idiosyncratic causes may involve highly individualistic responses to glacial-interglacial climate variation, as has been proposed for species in the Northern Hemisphere (Stewart et al. 2010). Alternatively, differences in patterns of spatial genetic structuring can arise from differences in reproductive behaviour. Abatus ingens and A. shackletoni have both been reported to exhibit pluriannual brooding cycles (Pearse \& McClintock 1990, Chenuil et al. 2004), but the reproductive behaviour of these Antarctic species is not yet completely understood. Moreover, in the Antarctic benthic ecosystem, our understanding of the environmental factors affecting species' fine-scale population genetic structure is very limited. In summer, millions of icebergs of different sizes move with ocean currents and wind drifts, causing massive disturbance in benthic communities (Barnes \& Conlan 2007). This could have an important effect on passive dispersal of brooders, resulting in spatially complex patterns of genetic connectivity that are inconsistent among species.

We should mention some limitations inherent to our study for detecting the impact of pollutants from Davis station on the genetic diversity and demographic history of the studied populations. The genetic signal of contemporary population declines can be confounded by the signal of historical events (Goossens et al. 2006). Previous applications of the Msvar method have failed to date known recent population declines when the genetic signature of a longer-term demographic change was present in the population (Beaumont 1999a, Storz et al. 2002). Thus, although the method is in fact able to detect contemporary human-induced demographic changes that occurred in the last decades (Goossens et al. 2006, Fontaine et al. 2012), it is possible that a recent decline would not be correctly dated for the presently studied populations. In addition, the observed connectivity between sites with different degrees of exposure to pollutants from the station could counteract any impact on genetic diversity due to increased mortality in impacted areas. Further assessment (e.g. at larger spatial scales) of the impact of Antarctic stations' effluents on the genetic diversity of benthic species is needed to understand potential long-term effects.

In summary, our results suggest that the 3 Abatus species studied in the near-shore Vestfold Hills region, East Antarctica, have suffered a long-term and remarkable population decline and that their present reduced effective population sizes could make them vulnerable to demographic, environmen- tal or genetic stochasticity. Although the estimated time when these species' populations started to decline precedes any potential effects from anthropogenic factors, recent declines may be concealed by the strength of this earlier demographic decline, and anthropogenic impacts should not be completely dismissed. The patterns of genetic structure observed in $A$. ingens and $A$. shackletoni seem to reflect historical signatures of survival in 2 different refugia during glacial cycles and secondary contact after recolonization of the study area. Contrary to previous evidence of fine-scale population structure in A. cordatus from the Kerguelen Islands, population connectivity at spatial scales of $5 \mathrm{~km}$ for these 3 brooding heart urchin species suggest that conditions in the Antarctic may promote dispersal to a greater extent than at the Kerguelen Islands, perhaps involving passive rafting on floating substrata.

Acknowledgements. The authors thank the Davis Station summer marine teams of 2009/10 and 2012/13 for assistance in field collections and laboratory processing of samples; particularly Jonathan Stark, Ian Aitkenhead and Patricia Corbett. This project was supported by the Australian Government through its Australian Antarctic Science Grants Program, awarded to K.J.M. (Project 3051) and C.K.K. (Project 4100).

\section{LITERATURE CITED}

Allcock AL, Strugnell JM (2012) Southern Ocean diversity: new paradigms from molecular ecology. Trends Ecol Evol 27:520-528

Anderson JB, Shipp SS, Lowe L, Wellner JS, Mosola AB (2002) The Antarctic ice sheet during the Last Glacial Maximum and its subsequent retreat history: a review. Quat Sci Rev 21:49-70

Baird HP, Miller KJ, Stark JS (2011) Evidence of hidden biodiversity, ongoing speciation and diverse patterns of genetic structure in giant Antarctic amphipods. Mol Ecol 20:3439-3454

> Baird HP, Miller KJ, Stark JS (2012) Genetic population structure in the Antarctic benthos: insights from the widespread amphipod, Orchomenella franklini. PLoS ONE 7:e34363

Barbosa SS, Klanten SO, Puritz JB, Toonen RJ, Byrne M (2013) Very fine-scale population genetic structure of sympatric asterinid sea stars with benthic and pelagic larvae: influence of mating system and dispersal potential. Biol J Linn Soc 108:821-833

- Barnes DKA, Conlan KE (2007) Disturbance, colonization and development of Antarctic benthic communities. Philos Trans R Soc Lond B 362:11-38

Barnes DKA, Peck LS (2008) Vulnerability of Antarctic shelf biodiversity to predicted regional warming. Clim Res 37: 149-163

Barnes DKA, Souster T (2011) Reduced survival of Antarctic benthos linked to climate-induced iceberg scouring. Nat Clim Change 1:365-368 
Beaumont MA (1999) Detecting population expansion and decline using microsatellites. Genetics 153:2013-2029

> Bradbury IR, Laurel B, Snelgrove PVR, Bentzen P, Campana SE (2008) Global patterns in marine dispersal estimates: the influence of geography, taxonomic category and life history. Proc R Soc Lond B 275:1803-1809

Brey T (1991) Population dynamics of Sterochinus antarcticus (Echinodermata: Echinoidea) on the Weddell Sea shelf and slope, Antarctica. Antarct Sci 3:251-256

> Chenuil A, Gault A, Feral JP (2004) Paternity analysis in the Antarctic brooding sea urchin Abatus nimrodi. A pilot study. Polar Biol 27:177-182

> Chikhi L, Sousa VC, Luisi P, Goossens B, Beaumont MA (2010) The confounding effects of population structure, genetic diversity and the sampling scheme on the detection and quantification of population size changes. Genetics 186:983-995

> Dayton PK, Robilliard GA, De Vries AL (1969) Anchor ice foundation in McMurdo Sound, Antarctica, and its biological effects. Science 163:273-274

> Diaz A, González-Wevar CA, Maturana CS, Palma AT, Poulin E, Gerard K (2012) Restricted geographic distribution and low genetic diversity of the brooding sea urchin Abatus agassizii (Spatangoidea: Schizasteridae) in the South Shetland Islands: a bridgehead population before the spread to the northern Antarctic Peninsula? Rev Chil Hist Nat 85:457-468

$>$ Domack E, O'Brien P, Harris P, Taylor F, Quilty PG, De Santis L, Raker B (1998) Late Quaternary sediment facies in Prydz Bay, East Antarctica and their relationship to glacial advance onto the continental shelf. Antarct Sci 10: 236-246

> Dumont CP, Himmelman JH, Robinson SMC (2007) Random movement pattern of the sea urchin Strongylocentrotus droebachiensis. J Exp Mar Biol Ecol 340:80-89

> Earl D, vonHoldt B (2012) STRUCTURE HARVESTER: a website and program for visualizing STRUCTURE output and implementing the Evanno method. Conserv Genet Resour 4:359-361

Evanno G, Regnaut S, Goudet J (2005) Detecting the number of clusters of individuals using the software structure: a simulation study. Mol Ecol 14:2611-2620

> Excoffier L, Smouse PE, Quattro JM (1992) Analysis of molecular variance inferred from metric distances among DNA haplotypes: application to human mitochondrial DNA restriction data. Genetics 131:479-491

Foll M, Gaggiotti O (2008) A genome-scan method to identify selected loci appropriate for both dominant and codominant markers: a Bayesian perspective. Genetics 180:977-993

> Fontaine MC, Snirc A, Frantzis A, Koutrakis E, Ozturk B, Ozturk AA, Austerlitz F (2012) History of expansion and anthropogenic collapse in a top marine predator of the Black Sea estimated from genetic data. Proc Natl Acad Sci USA 109:E2569-E2576

- Frankham R (1995) Conservation genetics. Annu Rev Genet 29:305-327

> Gautschi B, Tenzer I, Müller JP, Schmid B (2000a) Isolation and characterization of microsatellite loci in the bearded vulture (Gypaetus barbatus) and cross-amplification in three Old World vulture species. Mol Ecol 9:2193-2195

Gautschi B, Widmer A, Koella J (2000b) Isolation and characterization of microsatellite loci in the dice snake (Natrix tessellata). Mol Ecol 9:2192-2193

Gelman A, Rubin DB (1992) Inference from iterative simula- tion using multiple sequences. Stat Sci 7:457-511

> Glaubitz JC (2004) convert: a user-friendly program to reformat diploid genotypic data for commonly used population genetic software packages. Mol Ecol Notes 4: 309-310

González-Wevar CA, Saucede T, Morley SA, Chown SL, Poulin E (2013) Extinction and recolonization of maritime Antarctica in the limpet Nacella concinna (Strebel, 1908) during the last glacial cycle: toward a model of Quaternary biogeography in shallow Antarctic invertebrates. Mol Ecol 22:5221-5236

> Goossens B, Chikhi L, Ancrenaz M, Lackman-Ancrenaz I, Andau P, Bruford MW (2006) Genetic signature of anthropogenic population collapse in orang-utans. PLoS Biol 4:e25

Goudet J (1995) FSTAT (version 1.2): a computer program to calculate F-statistics. J Hered 86:485-486

Guo SW, Thompson EA (1992) Performing the exact test of Hardy-Weinberg proportion for multiple alleles. Biometrics 48:361-372

Hamilton MB, Pincus EL, Di Fiore A, Fleischer RC (1999) Universal linker and ligation procedures for construction of genomic DNA libraries enriched for microsatellites. Biotechniques 27:500-502, 504-507

> Hedrick PW (2005) A standardized genetic differentiation measure. Evolution 59:1633-1638

> Held C, Leese F (2007) The utility of fast evolving molecular markers for studying speciation in the Antarctic benthos. Polar Biol 30:513-521

> Hewitt G (2000) The genetic legacy of the Quaternary ice ages. Nature 405:907-913

> Hoffman JI, Clarke A, Clark MS, Peck LS (2013) Hierarchical population genetic structure in a direct developing antarctic marine invertebrate. PLoS ONE 8:e63954

> Hubisz MJ, Falush D, Stephens M, Pritchard JK (2009) Inferring weak population structure with the assistance of sample group information. Mol Ecol Resour 9:1322-1332

> Huybrechts P (2002) Sea-level changes at the LGM from icedynamic reconstructions of the Greenland and Antarctic ice sheets during the glacial cycles. Quat Sci Rev 21: 203-231

> Jost L (2008) $\mathrm{G}_{\mathrm{ST}}$ and its relatives do not measure differentiation. Mol Ecol 17:4015-4026

Kalinowski ST (2005) hp-rare 1.0: a computer program for performing rarefaction on measures of allelic richness. Mol Ecol Notes 5:187-189

Keenan K, McGinnity P, Cross TF, Crozier WW, Prodöhl PA, O'Hara RB (2013) diveRsity: an R package for the estimation and exploration of population genetics parameters and their associated errors. Methods Ecol Evol 4:782-788

Laurent A, Barbante C, Barnes PR, Barnola JM and others (2004) Eight glacial cycles from an Antarctic ice core. Nature 429:623-628

Ledoux JB, Tarnowska K, Gerard K, Lhuillier E and others (2012) Fine-scale spatial genetic structure in the brooding sea urchin Abatus cordatus suggests vulnerability of the Southern Ocean marine invertebrates facing global change. Polar Biol 35:611-623

Lischer HEL, Excoffier L (2012) PGDSpider: an automated data conversion tool for connecting population genetics and genomics programs. Bioinformatics 28:298-299

Meirmans PG (2006) Using the AMOVA framework to estimate a standarized genetic differentiation measure. Evolution 60:2399-2402

Miller KJ, Ayre DJ (2008) Population structure is not a sim- 
ple function of reproductive mode and larval type: insights from tropical corals. J Anim Ecol 77:713-724

Nei M (1973) Analysis of gene diversity in subdivided populations. Proc Natl Acad Sci USA 70:3321-3323

Nikula R, Spencer HG, Waters JM (2013) Passive rafting is a powerful driver of transoceanic gene flow. Biol Lett 9: 20120821

> O'Brien PE, De Santis L, Harris PT, Domack E, Quilty PG (1999) Ice shelf grounding zone features of western Prydz Bay, Antarctica: sedimentary processes from seismic and sidescan images. Antarct Sci 11:78-91

Palumbi SR (2003) Population genetics, demographic connectivity, and the design of Marine Reserves. Ecol Appl 13:146-158

> Peakall R, Smouse PE (2012) GenAlEx 6.5: genetic analysis in Excel. Population genetic software for teaching and research — an update. Bioinformatics 28:2537-2539

Pearse JS, McClintock JB (1990) A comparison of reproduction by the brooding spatangoid echinoids Abatus shackletoni and Abatus nimrodi in Mcmurdo Sound, Antarctica. Invertebr Reprod Dev 17:181-191

Plummer M, Best N, Cowles K, Vines K (2006) CODA: convergence diagnosis and output analysis for MCMC. $\mathrm{R}$ News 6:7-11

Poulin E, Feral JP (1994) The fiction and the facts of Antarctic brood protecting - population genetics and evolution of schizasterid echinoids. In: David B, Guille A, Feral J-P, Roux M (eds) Echinoderms through time. Proc 8th Int Echinoderm Conf, Dijon, 6-10 September 1993. A. A. Balkema, Rotterdam, p 837-844

Poulin E, Palma AT, Feral JP (2002) Evolutionary versus ecological success in Antarctic benthic invertebrates. Trends Ecol Evol 17:218-222

Pritchard JK, Stephens M, Donnelly P (2000) Inference of population structure using multilocus genotype data. Genetics 155:945-959

Raymond M, Rousset F (1995) GENEPOP (Version 1.2): population genetics software for exact tests and ecumenicism. J Hered 86:248-249

Rice WR (1989) Analyzing tables of statistical tests. Evolution 43:223-225

Riginos C, Douglas KE, Jin Y, Shanahan DF, Treml EA (2011) Effects of geography and life history traits on genetic differentiation in benthic marine fishes. Ecography 34:566-575

Ritchie PA, Millar CD, Gibb GC, Baroni C, Lambert DM (2004) Ancient DNA enables timing of the Pleistocene origin and Holocene expansion of two Adélie penguin lineages in Antarctica. Mol Biol Evol 21:240-248

Rogers AD (2007) Evolution and biodiversity of Antarctic organisms: a molecular perspective. Philos Trans R Soc

Editorial responsibility: Peter Steinberg,

Sydney, New South Wales, Australia
Lond B 362:2191-2214

> Selkoe KA, Toonen RJ (2011) Marine connectivity: a new look at pelagic larval duration and genetic metrics of dispersal. Mar Ecol Prog Ser 436:291-305

Stark JS, Kim SL, Oliver JS (2014) Anthropogenic disturbance and biodiversity of marine benthic communities in Antarctica: a regional comparison. PLoS ONE 9:e98802

Stark JS, Smith J, King CK, Lindsay M and others (2015) Physical, chemical, biological and ecotoxicological properties of wastewater discharged from Davis Station, Antarctica. Cold Reg Sci Technol 113:52-62

- Stewart JR, Lister AM, Barnes I, Dalen L (2010) Refugia revisited: individualistic responses of species in space and time. Proc R Soc Lond B 277:661-671

Storz JF, Beaumont MA (2002) Testing for genetic evidence of population expansion and contraction: an empirical analysis of microsatellite DNA variation using a hierarchical Bayesian model. Evolution 56:154-166

Storz JF, Beaumont MA, Alberts SC (2002) Genetic evidence for long-term population decline in a savannah-dwelling primate: inferences from a hierarchical Bayesian model. Mol Biol Evol 19:1981-1990

> Thatje S (2012) Effects of capability for dispersal on the evolution of diversity in Antarctic benthos. Integr Comp Biol 52:470-482

Thatje S, Hillenbrand CD, Larter R (2005) On the origin of Antarctic marine benthic community structure. Trends Ecol Evol 20:534-540

Thatje S, Hillenbrand CD, Mackensen A, Larter R (2008) Life hung by a thread: endurance of Antarctic fauna in glacial periods. Ecology 89:682-692

Tison JL, Blennow V, Palkopoulou E, Gustafsson P, Roos A, Dalén L (2015) Population structure and recent temporal changes in genetic variation in Eurasian otters from Sweden. Conserv Genet 16:371-384

- Van Oosterhout C, Hutchinson WF, Wills DPM, Shipley P (2004) micro-checker: software for identifying and correcting genotyping errors in microsatellite data. Mol Ecol Notes 4:535-538

Weir BS (1996) Genetic data analysis II: methods for discrete population genetic data. Sinauer Associates, Sunderland, MA

Weir BS, Cockerham CC (1984) Estimating F-statistics for the analysis of population structure. Evolution 38: 1358-1370

Wright S (1943) Isolation by distance. Genetics 28:114-138

Zemlak TS, Habit EM, Walde SJ, Battini MA, Adams ED, Ruzzante DE (2008) Across the southern Andes on fin: glacial refugia, drainage reversals and a secondary contact zone revealed by the phylogeographical signal of Galaxias platei in Patagonia. Mol Ecol 17:5049-5061

Submitted: February 5, 2015; Accepted: November 25, 2015 Proofs received from author(s): February 26, 2016 